\title{
REVIEW
}

\section{Hepatic metabolic regulation by nuclear factor E4BP4}

\author{
Zifeng Zhao',2, Lei Yin ${ }^{2}$, Feihua $\mathbf{W u}^{1}$ and Xin Tong ${ }^{2}$ \\ 1Department of Pharmacology of Chinese Materia Medica, School of Traditional Chinese Pharmacy, China Pharmaceutical University, Nanjing, Jiangsu \\ Province, China \\ 2Department of Molecular \& Integrative Physiology, University of Michigan Medical School, Ann Arbor, Michigan, USA
}

Correspondence should be addressed to F Wu or X Tong: fhwu2000@cpu.edu.cn or xintong@umich.edu

\begin{abstract}
Discovered as a b-ZIP transcription repressor 30 years ago, E4 promoter-binding protein 4 (E4BP4) has been shown to play critical roles in immunity, circadian rhythms, and cancer progression. Recent research has highlighted E4BP4 as a novel regulator of metabolisms in various tissues. In this review, we focus on the function and mechanisms of hepatic E4BP4 in regulating lipid and glucose homeostasis, bile metabolism, as well as xenobiotic metabolism. Finally, E4BP4-specific targets will be discussed for the prevention and treatment of metabolic disorders.
\end{abstract}

\author{
Key Words \\ - E4BP4 \\ - insulin \\ - lipid \\ - glucose \\ metabolism
}

Journal of Molecular Endocrinology

(2021) 66, R15-R21

\section{Introduction}

The PAR proteins, named after the conserved prolineand acid-rich (PAR) domains in a subset of basic leucine zipper (b-ZIP) transcription factors, consist of four family members, TEF/VBP, HLF, DBP, and E4BP4 (Cowell \& Hurst 1994). The PAR family proteins form homodimers or hetero-dimerize within other family proteins and function as either transcription activators or repressors (Hai \& Hartman 2001). The PAR family proteins have been found to have diverse physiological functions in mammals, including circadian rhythms, immunoregulation, and cancer development (Green 2016). This review will focus on the role of $\mathrm{E} 4$ promoter-binding protein 4 (E4BP4), also named as nuclear factor, interleukin 3 regulated (NFIL3), the least known PAR transcription factor, in liver metabolic regulation. NFIL3/E4BP4 was initially cloned as a b-ZIP transcription factor that binds to the consensus sequence $(\mathrm{G} / \mathrm{A}) \mathrm{T}(\mathrm{G} / \mathrm{T}) \mathrm{A}(\mathrm{C} / \mathrm{T}) \mathrm{GTAA}(\mathrm{C} / \mathrm{T})$ in the adenoviral E4 promoter DNA (Cowell et al. 1992). Further analysis revealed that E4BP4 functions as a transcription repressor with its repression activity primarily located in its C-terminal region (Cowell \& Hurst 1994) (Fig. 1). Although Northern blotting analysis indicates the E4bp4 mRNA was ubiquitously expressed in various cell lines and mouse tissues, very low abundance of the E4BP4 protein was detected in most cases, suggesting that the E4BP4 protein level is likely controlled at both the translational and post-translational levels (Chen et al. 1995).

One of the best-known biological functions of E4BP4 is related to immunomodulation (Male et al. 2012). The E4bp4 promoter was found to be activated by interleukin 3 in T lymphocytes, giving rise to its other name NF-IL3 (Zhang et al. 1995). Subsequently, multiple studies have illuminated the essential role of E4BP4 in NK cell development/maturation as well as the development of innate lymphoid cells (ILC) (Geiger et al. 2014). E4BP4 also functions as a key regulator of IL 3-dependent pro-B lymphocyte survival and immunoglobulin class switch (Ikushima et al. 1997). Moreover, E4BP4 was shown to 


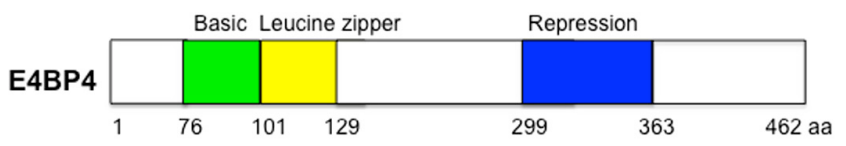

Figure 1

Schematic of E4BP4 functional domains. A full color version of this figure is available at https://doi.org/10.1530/JME-20-0239.

regulate cytokine production and the effector functions in a subsets of T lymphocytes (Kashiwada et al. 2011). Given its broad actions in multiple immune cells, it was speculated that E4BP4 might be relevant in human immune disorders. Indeed, E4BP4 has been reported to be implicated in the pathogenesis of IBD, MS, and systemic lupus erythematosis (Yin et al. 2017).

As a protein wearing multiple hats, E4BP4 has also been identified as a key circadian output oscillator in the molecular circadian clock system. In its core, the circadian clock comprises a transcription-translational feedback loop driven by key circadian proteins including BMAL1, CLOCK, PERIOD, CRY, and nuclear receptors (NR1D1 and RORs) (Partch et al. 2014). The E4bp 4 mRNA expression was shown to display a classical circadian oscillation pattern that was blunted in the Bmal1-/- mice, supporting that E4bp4 is a direct output gene of the molecular circadian clock (Chen et al. 2019b). E4BP4 was also found to interact with the core clock protein CRY2 in cultured cells (Ohno et al. 2007). However, deletion of E4bp4 showed little impact on the oscillations of core clock genes. Most recently, the Lazar group has shown that the rhythmic expression of E4bp 4 was disrupted in Kupffer cells from the liver of adult hepatocyte-specific Rev-erb $\alpha$ and Rev-erb $\beta$ double knockout mice, highlighting an essential role of the hepatic clock in coordinating metabolic events in the liver (Guan et al. 2020). Given the extensive expression of E4BP4 in a variety of tissues, it is likely that E4BP4 may control a subset of circadian output genes in a tissuespecific manner.

\section{E4BP4 in liver metabolism}

Liver is the central organ in charge of metabolic homeostasis in mammals. During the cycles of food intake, liver turns on anabolic metabolism upon feeding and switches to catabolic metabolism during fasting (Rui 2014). This switch between different metabolic pathways is tightly controlled at both the transcriptional and post-translational levels. A panel of transcription factors sensitive to the nutrient status have been identified as critical regulators in maintaining metabolic homeostasis in the liver (Wang et al. 2016, Hatting et al. 2018).
For instance, SREBP-1c, FXR, and ChREBP have been identified as critical transcription factors in lipid and bile acid biosynthesis during feeding (Chiang 2013, Wang et al. 2015), whereas FOXO1, CREB, and PPAR $\alpha$ are required in gluconeogenesis and lipid oxidation during fasting (Rui 2014, Wang et al. 2016). Although the E4bp4 expression was shown to be most abundant in the liver, the regulation of its mRNA by nutrients and hormone signaling has been largely uncharacterized. Our lab has discovered that refeeding induces the E4bp 4 mRNA and protein in the mouse liver (Tong et al. 2010). We also found that insulin potently induces E4bp4 expression through the AKT/mTORC1/SREBP-1c pathway (Tong et al. 2016). Most recently, we reported that chemical or diet-induced ER stress potently induces hepatic E4BP4 to promote lipid accumulation via the suppression of AMPK pathway (Yang et al. 2020). Altogether, these data suggest that E4BP4 could be a critical player during anabolic metabolism.

\section{E4BP4 in lipid metabolism}

\section{E4BP4 and FGF21-promoted fatty acid oxidation}

During fasting, liver turns on lipolysis to break down triglycerides to release free fatty acids (FFAs) for fatty acid oxidation and ATP production inside the mitochondria (Rui 2014). The nuclear receptor PPAR $\alpha$ plays a dominant role in activating fatty acid oxidation genes in the liver during fasting (Bougarne et al. 2018). Ppara-lmice were shown to develop liver steatosis along with the suppression of FAO gene expression under food deprivation (Sugden et al. 2002, Lee et al. 2004, Bougarne et al. 2018). One of the PPAR $\alpha$ targets is FGF21, a hepatic hormone critical for energy mobilization during fasting (Badman et al. 2007, Inagaki et al. 2007). Once released from liver, FGF21 can stimulate adipocyte lipolysis in white and brown adipose tissues and increase the levels of FFAs in circulation. We observed that E4BP4 represses the Fgf21 expression in a circadian fashion in hepatocytes. The Fgf21 mRNA oscillations were anti-phase to those of E4bp 4 during a circadian cycle in the mouse liver (Tong et al. 2010). We also detected a drastic decrease in the level of FGF21 in the medium from primary mouse hepatocytes transduced with Ad-E4bp4. Our chromatin immunoprecipitation (CHIP) assay uncovered the direct binding of E4BP4 to the $F \& 21$ promoter, consistent with its potent repression of the $F g f 21$ expression in hepatocytes. We further confirmed the physiological role of E4BP4 as a suppressor of FGF21 in hepatocytes in response to insulin. Later on, we reported that G9a, 
a histone methyl-transferase, is required to mediate the suppression of FGF21 by E4BP4 in hepatocytes (Tong et al. 2013). In contrast, CREBH, an ER-sensitive transcription factor, has been shown to facilitate the PPAR $\alpha$-stimulated Fgf21 expression in the liver during fasting (Zheng et al. 2016). The Zhang group reported that E4BP4 interacts with CREBH and antagonizes the CREBH-mediated activation of FGF21 in the liver (Zheng et al. 2016, Bhattacharya et al. 2018). Collectively, these results suggest that $\mathrm{E} 4 \mathrm{BP} 4$ might contribute to catabolism of lipids by suppressing hepatic FGF21 in response to insulin during feeding.

\section{E4BP4 and insulin-induced de novo lipogenesis}

During food intake, liver activates anabolic lipid metabolism via insulin to upregulate de novo lipogenesis and cholesterol biosynthesis (Rui 2014). Once bound to the insulin receptor on hepatocytes, insulin activates the PI3K-AKT-mTORC1 signaling cascade. The Goldstein lab discovered that insulin potently induces the lipogenic master sterol regulatory element-binding protein 1 (SREBP-1) downstream of AKT-mTORC1, which in turn upregulates the mRNA levels of key enzymes for lipogenesis such as Fasn, Acc1, Atp-cl, and Scd1 (Brown \& Goldstein 1997, Horton et al. 2002). SREBP-1 is a member of the basic-helix-loop-helix (bHLH) leucine zipper transcription factors (Shimano 2001). SREBP-1 consists of both SREBP-1a and SREBP-1c isoforms. SREBP-1a is mainly expressed in the intestine and spleen, whereas SREBP-1c is the predominant isoform in the liver (Shimano 2001). The factors that regulate the SREBP-1c transcription, processing, and stability have been shown to impact the degree of hepatic lipid biosynthesis and diet-induced liver steatosis.

We recently reported that insulin stimulates both the mRNA and protein abundance of E4BP4 in mouse hepatocytes via the classical AKT-mTORC1-SREBP-1c pathway (Tong et al. 2016). E4bp4-deleted hepatocytes display a more than $50 \%$ reduction in the rate of de novo lipogenesis and the expression of lipogenic enzymes. We detected a marked reduction of nuclear SREPB-1c in the E4bp4-deleted primary mouse hepatocytes. Adenoviral overexpression of E4BP4 enhances the nuclear abundance of SREBP-1c in a feed-forward feedback loop. More interestingly, the pro-lipogenic action of E4BP4 relies on its ability to enhance the SREBP-1c acetylation via proteinprotein interaction. These findings strongly indicate that hepatic E4BP4 is a prolipogenic factor downstream of the insulin signaling.

\section{E4BP4 in glucose metabolism}

Liver is also critical for maintaining glucose homeostasis (Rui 2014). After food intake, liver synthesizes glycogen and inhibits gluconeogenesis. In contrast, liver undergoes glycogenolysis and gluconeogenesis to maintain blood glucose level during fasting. These metabolic processes are tightly controlled by a panel of hormonal and nutritional signals (Rui 2014, Petersen et al. 2017). Insulin promotes glycogen synthesis mainly by stimulating the phosphorylation of GSK3 and inhibits gluconeogenesis by enhancing the FOXO1 phosphorylation (Lee \& Dong 2017, Bergman et al. 2019). During fasting, the glucagon signaling activates the PKA-CREB pathway and triggers glycogenolysis and gluconeogenesis in the liver (Ravnskjaer et al. 2016). Many factors that influence either the insulin-AKTFOXO axis or the glucagon-PKA-CREB signaling could impact liver glucose metabolism and consequently systemic glucose homeostasis.

Recently, the Koo group has reported the in vivo role of E4BP4 in glucose metabolism, suggesting that E4BP4 may down-regulate gluconeogenesis in the liver (Kang et al. 2017). They found that E4BP4 reduces glucose production and suppresses the gluconeogenic genes including G6pase and Pepck in part through competing with CREB. Ectopic expression of E4BP4 in the liver of $o b / o b$ mice ameliorated hyperglycemia and glucose intolerance. On the flip side, acute depletion of E4bp4 in the mouse liver elevated blood glucose and the expression of hepatic gluconeogenic genes. These findings are in line with our own unpublished data supporting the role of E4BP4 as an insulin-induced gene and the ability of E4BP4 to suppress the $P g C-1 \alpha$ transcription.

So far, whether E4BP4 contributes to impaired glucose metabolism during obesity remains controversial. The Koo group found that the protein but not mRNA level of E4BP4 was reduced in the liver of $o b / o b$ mice after 27-week high-fat diet feeding, possibly due to the impaired E4BP4 protein stability in the insulin-resistant mouse liver (Kang et al. 2017). K. Hofmann et al. found that streptozotocin (STZ)-induced diabetes did not affect the E4bp4 mRNA level. Their data showed a loss of diurnal rhythm in the expression of $E 4 b p 4$ in spontaneous type 1 diabetic male rats (Hofmann et al. 2013). In addition, the Gimble group reported that the E4BP4 mRNA level displays a positive correlation with BMI in the overweight young (age < 36 years) people ( $\mathrm{Wu}$ et al. 2009). More research using a variety of animal models is needed to clarify the role of E4BP4 in glucose metabolism in the liver. 


\section{E4BP4 in bile acid metabolism}

Liver is also the primary organ for the biosynthesis of bile acids from cholesterol. Conversion of cholesterol into bile acids requires a complex biosynthetic pathway involving up to 17 enzymatic steps (Chiang 2013). CYP7A1 represents the rate-limiting enzyme of the bile acid biosynthesis. One of the major regulators of bile acid metabolism is the bile acid-activated nuclear receptor farnesoid X receptor (FXR) (Urizar et al. 2000, Huang et al. 2006, Preidis et al. 2017). Extensive research from multiple groups has established the model by which FXR inhibits hepatic CYP7A1 expression. FXR was shown to indirectly suppress the Cyp7a1 transcription by inducing both small heterodimer partner (SHP) in the liver and fibroblast growth factor-15 in the intestine (Goodwin et al. 2000, Inagaki et al. 2005, Huang et al. 2006, Shin \& Osborne 2009, Kliewer \& Mangelsdorf 2015, Byun et al. 2017, Preidis et al. 2017). In a luciferase reporter assay, E4BP4 overexpression potently suppressed the Cyp7A1 promoter-driven luciferase activity (Noshiro et al. 2007). Other studies have provided indirect evidence for E4BP4 as a physiological regulator of Cyp7a1 expression and bile acid metabolism. In a mouse model with increased hypoxia signaling in the liver, elevated E4BP4 leads to the suppression of hepatic Cyp7a1 (Ramakrishnan et al. 2014). In another study, E4BP4 was found to directly bind to the Cyp7A1 promoter by ChIP assay (Yoshitane et al. 2019). As of now, whether E4BP4 is required for controlling the diurnal expression of hepatic $C y p 7 A 1$ remains to be established.

\section{E4BP4 in xenobiotic metabolism}

Liver is the primary organ to carry out xenobiotic metabolism of drugs, pollutants, and toxins (Zhang et al. 2018). Xenobiotic metabolism depends on three type of enzymes: Phase I enzymes modify the substrates, Phase II enzymes conjugate the substrates, and Phase III enzymes excrete the end products. P450 (CYP) enzymes are the most abundant among Phase I enzymes responsible for clearing drugs in the liver. In the mouse liver, several cytochrome P450 enzymes including Cyp17, Cyp2a4, and Cyp2e1 were shown to display a diurnal oscillation in their mRNA expression (Manikandan \& Nagini 2018, Tornio \& Backman 2018, Zhang et al. 2018, Chen et al. 2019a). E4BP4 was also reported to control the expression of CYP3A4 (Cyp3a11 in mice), one of the most important enzymes for drug metabolism and detoxification (Tong et al. 2019). Takiguchi et al. found that in synchronized human hepatoma cells HepG2, the mRNA levels of Cyp3A4, Dbp, and E4bp4 exhibited a 24-h oscillation (Takiguchi et al. 2007). They also found that DBP overexpression activates the promoter of Cyp3A4, whereas E4BP4 does the opposite in an in vitro luciferase reporter assay. Moreover, the CYP3A4 protein and activity were found to increase in the liver of $E 4 b p 4^{-/-}$mice, resulting in altered pharmacokinetics of Midazolam (Takiguchi et al. 2007).

Carboxylesterases (CES) are a family of Phase I enzymes that play an important role in xenobiotic clearance and lipid metabolism. One of CES proteins, CES2, was found to be reduced in the liver of $E 4 b p 4^{-/-}$ mice. This reduction led to slowed metabolism of its main substrate CPT-11 (irinotecan) (Zhao et al. 2018). Flavin-containing monooxygenase 5 (FMO5) is another important Phase I enzyme in xenobiotic metabolism in the liver. Hepatic Fmo5 expression was found to be upregulated and its circadian rhythm was attenuated in $E 4 b p 4^{-/-}$mice. All these findings support E4BP4 as a novel regulator of the pharmacokinetics of detoxification enzymes. Identification of the underlying mechanisms could lead to a better understanding of how the molecular circadian clock system influences drug metabolism in the liver (Chen et al. 2019b).

\section{E4BP4 in obesity and metabolic syndrome}

The ever-increasing prevalence of obesity leads to type 2 diabetes, cardiovascular-renal complications, and many types of cancers worldwide. Obesity is likely to be a result of both altered lifestyles and genetic susceptibilities. Nowadays, circadian disruption/misalignment has garnered a lot of attention as one of the major contributors to metabolic dysfunction and obesity (Rana et al. 2003, Zvonic et al. 2006, Wu et al. 2009). Several studies have found that high-fat diet feeding dampens the amplitude of circadian genes while altering the period of molecular clock system in multiple tissues of rodents (Kohsaka et al. 2007, Kaneko et al. 2009, Hatori et al. 2012). Specifically, the circadian oscillations of $D b p$ and $E 4 b p 4$, two direct circadian output genes, were largely lost in both the liver and kidney of those highfat diet-fed mice (Hsieh et al. 2010).

So far, whether E4BP4 could be involved in metabolic dysfunction after high-fat diet feeding remains largely undetermined. Several studies suggest that E4BP4 could regulate obesity in a tissue-specific manner. The Lee group reported that E4BP4 is required for the accumulation of NK cells in the adipose tissue upon high-fat diet feeding 


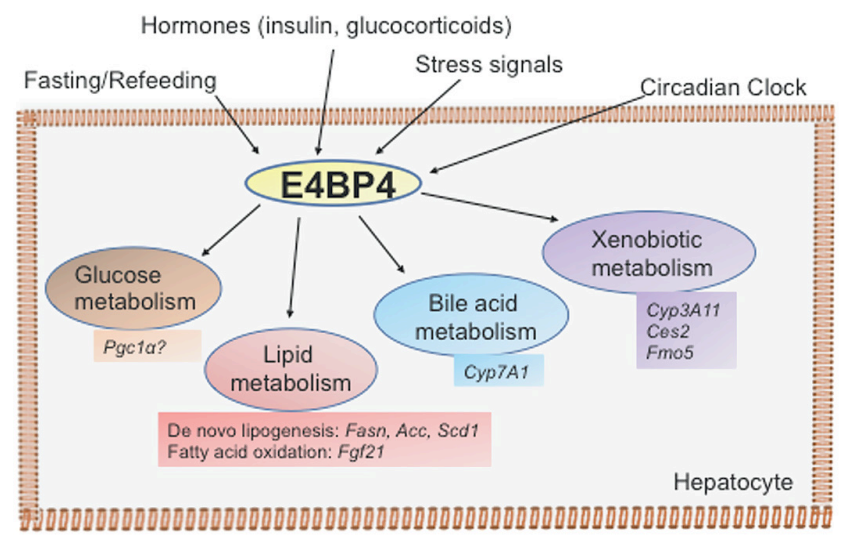

Figure 2

Overview of metabolic actions of E4BP4 in the liver. Hepatic E4BP4 expression and activity are likely to be sensitive to the cycle of fasting/ refeeding, hormones, stress signals, and the circadian clock. Hepatic E4BP4 regulates lipid metabolism, glucose metabolism, bile acid metabolism, and xenobiotic metabolism to impact the whole body homeostasis. A full color version of this figure is available at https://doi. org/10.1530/JME-20-0239.

(Lee et al. 2016). E4bp4-/- mice were shown to be resistant to diet-induced adipose inflammation along with improved insulin resistance (Lee et al. 2016). The Hoover group discovered that E4BP4 in intestinal epithelial cells controls the expression of a circadian lipid metabolic program and regulates lipid absorption and export. Intriguingly, they found that microbiota regulates body composition by modulating the circadian oscillations of E4bp4 within enterocytes (Wang et al. 2017). In our most recent study, we discovered that both ER stress inducer tunicamycin and high-fat low methionine and cholinedeficient (HFLMCD) diet induce E4BP4 and promote lipid accumulation in the liver. Using hepatocyte-specific E4bp4 knockout mice, we have found that loss of hepatic E4bp4 protects mice against HFLMCD diet-induced liver steatosis and hepatocyte injury. Mechanistically, we show that $E 4 b p 4$ is most likely to promote lipid droplet formation by suppressing the AMPK pathway in hepatocytes (Z Zhao, L Yin, F Wu \& X Tong, unpublished observations).

\section{Conclusion and future directions}

In summary, recent findings have highlighted the novel role of E4BP4 in regulating metabolism and metabolic diseases, supporting that E4BP4 could be an important regulator of glucose, triglycerides, cholesterol, and xenobiotic metabolism in the liver. It has become increasingly clear that E4BP4 impacts various metabolic pathways via its specific regulation of a subset of genes in different tissues. Given the complexity of its functions,
E4BP4 can either repress or activate the gene expression of metabolic pathways through completely different mechanisms (Fig. 2). Currently, the biochemical basis for this functional switch remains unknown. Therefore, an in-depth understanding of how E4BP4 controls the expression of its targets in different tissues is crucial to identifying unique drug targets for the prevention and treatment metabolic disorders such as diabetes and NAFLD.

\section{Declaration of interest}

The authors declare that there is no conflict of interest that could be perceived as prejudicing the impartiality of this review.

\section{Funding}

This work is supported by NIH R00 (DK077449) and R01 (DK099593) to L Y, and R01 (DK121170) to X T. Part of the work was also supported by pilot grants from Michigan Nutrition Obesity Research Center to $L Y$ and $X T$ (P30 DK089503), Michigan Diabetes Research Training Center to $L Y$ and $X$ T (P30 DK020570). This work was also partly supported by the 'Exploration World Student Scholarship Funding Program' of China Pharmaceutical University.

\section{References}

Badman MK, Pissios P, Kennedy AR, Koukos G, Flier JS \& Maratos-Flier E 2007 Hepatic fibroblast growth factor 21 is regulated by PPARalpha and is a key mediator of hepatic lipid metabolism in ketotic states. Cell Metabolism 5 426-437. (https://doi.org/10.1016/j. cmet.2007.05.002)

Bergman RN, Piccinini F, Kabir M \& Ader M 2019 Novel aspects of the role of the liver in carbohydrate metabolism. Metabolism: Clinical and Experimental 99 119-125. (https://doi.org/10.1016/j. metabol.2019.05.011)

Bhattacharya A, Sun S, Wang H, Liu M, Long Q, Yin L, Kersten S, Zhang K \& Qi L 2018 Hepatic Sel1L-Hrd1 ER-associated degradation (ERAD) manages FGF21 levels and systemic metabolism via CREBH. EMBO Journal 37 e99277. (https://doi.org/10.15252/embj.201899277)

Bougarne N, Weyers B, Desmet SJ, Deckers J, Ray DW, Staels B \& De Bosscher K 2018 Molecular actions of PPARalpha in lipid metabolism and inflammation. Endocrine Reviews 39 760-802. (https://doi. org/10.1210/er.2018-00064)

Brown MS \& Goldstein JL 1997 The SREBP pathway: regulation of cholesterol metabolism by proteolysis of a membrane-bound transcription factor. Cell 89 331-340. (https://doi.org/10.1016/s00928674(00)80213-5)

Byun S, Kim YC, Zhang Y, Kong B, Guo G, Sadoshima J, Ma J, Kemper B \& Kemper JK 2017 A postprandial FGF19-SHP-LSD1 regulatory axis mediates epigenetic repression of hepatic autophagy. EMBO Journal 36 1755-1769. (https://doi.org/10.15252/embj.201695500)

Chen WJ, Lewis KS, Chandra G, Cogswell JP, Stinnett SW, Kadwell SH \& Gray JG 1995 Characterization of human E4BP4, a phosphorylated bZIP factor. Biochimica et Biophysica Acta 1264 388-396. (https://doi. org/10.1016/0167-4781(95)00182-4)

Chen J, Jiang S, Wang J, Renukuntla J, Sirimulla S \& Chen J 2019a A comprehensive review of cytochrome P450 2E1 for xenobiotic metabolism. Drug Metabolism Reviews 51 178-195. (https://doi.org/10 .1080/03602532.2019.1632889) 
Chen M, Guan B, Xu H, Yu F, Zhang T \& Wu B 2019b The molecular mechanism regulating diurnal rhythm of flavin-containing monooxygenase 5 in mouse liver. Drug Metabolism and Disposition 47 1333-1342. (https://doi.org/10.1124/dmd.119.088450)

Chiang JYL 2013 Bile acid metabolism and signaling. Comprehensive Physiology 3 1191-1212. (https://doi.org/10.1002/cphy.c120023)

Cowell IG \& Hurst HC 1994 Transcriptional repression by the human BZIP factor E4BP4 - definition of a minimal repression domain. Nucleic Acids Research 22 59-65. (https://doi.org/10.1093/nar/22.1.59)

Cowell IG, Skinner A \& Hurst HC 1992 Transcriptional repression by a novel member of the BZIP family of transcription factors. Molecular and Cellular Biology 12 3070-3077. (https://doi.org/10.1128/ mcb.12.7.3070)

Geiger TL, Abt MC, Gasteiger G, Firth MA, O'Connor MH, Geary CD, O'Sullivan TE, van den Brink MR, Pamer EG, Hanash AM, et al. 2014 Nfil3 is crucial for development of innate lymphoid cells and host protection against intestinal pathogens. Journal of Experimental Medicine 211 1723-1731. (https://doi.org/10.1084/jem.20140212)

Goodwin B, Jones SA, Price RR, Watson MA, McKee DD, Moore LB, Galardi C, Wilson JG, Lewis MC, Roth ME, et al. 2000 A regulatory cascade of the nuclear receptors FXR, SHP-1, and LRH-1 represses bile acid biosynthesis. Molecular Cell 6 517-526. (https://doi. org/10.1016/s1097-2765(00)00051-4)

Green CB 2016 Circadian post-transcriptional control of metabolism. In A Time for Metabolism and Hormones, pp. 41-50. Eds P Sassone-Corsi \& Y Christen. Berlin, Germany: Springer. (https://doi. org/10.1007/978-3-319-27069-2_5)

Guan D, Xiong Y, Trinh TM, Xiao Y, Hu W, Jiang C, Dierickx P, Jang C, Rabinowitz JD \& Lazar MA 2020 The hepatocyte clock and feeding control chronophysiology of multiple liver cell types. Science 369 1388-1394. (https://doi.org/10.1126/science.aba8984)

Hai T \& Hartman MG 2001 The molecular biology and nomenclature of the activating transcription factor/cAMP responsive element binding family of transcription factors: activating transcription factor proteins and homeostasis. Gene 273 1-11. (https://doi.org/10.1016/ s0378-1119(01)00551-0)

Hatori M, Vollmers C, Zarrinpar A, DiTacchio L, Bushong EA, Gill S, Leblanc M, Chaix A, Joens M, Fitzpatrick JA, et al. 2012 Timerestricted feeding without reducing caloric intake prevents metabolic diseases in mice fed a high-fat diet. Cell Metabolism 15 848-860. (https://doi.org/10.1016/j.cmet.2012.04.019)

Hatting M, Tavares CDJ, Sharabi K, Rines AK \& Puigserver P 2018 Insulin regulation of gluconeogenesis. Annals of the New York Academy of Sciences 1411 21-35. (https://doi.org/10.1111/ nyas.13435

Hofmann K, Schoenerstedt U, Muehlbauer E, Wedekind D \& Peschke E 2013 Clock gene expression in the liver of streptozotocin-induced and spontaneous Type 1 diabetic rats. Hormone and Metabolic Research 45 629-639. (https://doi.org/10.1055/s-0033-1343462)

Horton JD, Goldstein JL \& Brown MS 2002 SREBPs: activators of the complete program of cholesterol and fatty acid synthesis in the liver. Journal of Clinical Investigation 109 1125-1131. (https://doi. org/10.1172/JCI15593)

Hsieh MC, Yang SC, Tseng HL, Hwang LL, Chen CT \& Shieh KR 2010 Abnormal expressions of circadian-clock and circadian clockcontrolled genes in the livers and kidneys of long-term, high-fatdiet-treated mice. International Journal of Obesity 34 227-239. (https://doi.org/10.1038/ijo.2009.228)

Huang W, Ma K, Zhang J, Qatanani M, Cuvillier J, Liu J, Dong B \& Moore DD 2006 Nuclear receptor-dependent bile acid signaling is required for normal liver regeneration. Science 312 233-236. (https:// doi.org/10.1126/science.1121435)

Ikushima S, Inukai T, Inaba T, Nimer SD, Cleveland JL \& Look AT 1997 Pivotal role for the NFIL3/E4BP4 transcription factor in interleukin 3-mediated survival of pro-B lymphocytes. PNAS 94 2609-2614. (https://doi.org/10.1073/pnas.94.6.2609)
Inagaki T, Choi M, Moschetta A, Peng L, Cummins CL, McDonald JG, Luo G, Jones SA, Goodwin B, Richardson JA, et al. 2005 Fibroblast growth factor 15 functions as an enterohepatic signal to regulate bile acid homeostasis. Cell Metabolism 2 217-225. (https://doi. org/10.1016/j.cmet.2005.09.001)

Inagaki T, Dutchak P, Zhao G, Ding X, Gautron L, Parameswara V, Li Y, Goetz R, Mohammadi M, Esser V, et al. 2007 Endocrine regulation of the fasting response by PPARalpha-mediated induction of fibroblast growth factor 21. Cell Metabolism 5 415-425. (https://doi. org/10.1016/j.cmet.2007.05.003)

Kaneko K, Yamada T, Tsukita S, Takahashi K, Ishigaki Y, Oka Y \& Katagiri H 2009 Obesity alters circadian expressions of molecular clock genes in the brainstem. Brain Research 1263 58-68. (https:// doi.org/10.1016/j.brainres.2008.12.071)

Kang G, Han HS \& Koo SH 2017 NFIL3 is a negative regulator of hepatic gluconeogenesis. Metabolism: Clinical and Experimental 77 13-22. (https://doi.org/10.1016/j.metabol.2017.08.007)

Kashiwada M, Cassel SL, Colgan JD \& Rothman PB 2011 NFIL3/E4BP4 controls type $2 \mathrm{~T}$ helper cell cytokine expression. EMBO Journal 30 2071-2082. (https://doi.org/10.1038/emboj.2011.111)

Kliewer SA \& Mangelsdorf DJ 2015 Bile acids as hormones: the FXRFGF15/19 pathway. Digestive Diseases 33 327-331. (https://doi. org/10.1159/000371670)

Kohsaka A, Laposky AD, Ramsey KM, Estrada C, Joshu C, Kobayashi Y, Turek FW \& Bass J 2007 High-fat diet disrupts behavioral and molecular circadian rhythms in mice. Cell Metabolism 6 414-421. (https://doi.org/10.1016/j.cmet.2007.09.006)

Lee S \& Dong HH 2017 FoxO integration of insulin signaling with glucose and lipid metabolism. Journal of Endocrinology 233 R67-R79. (https://doi.org/10.1530/JOE-17-0002)

Lee SS, Chan WY, Lo CK, Wan DC, Tsang DS \& Cheung WT 2004 Requirement of PPARalpha in maintaining phospholipid and triacylglycerol homeostasis during energy deprivation. Journal of Lipid Research 45 2025-2037. (https://doi.org/10.1194/jlr.M400078JLR200)

Lee BC, Kim MS, Pae M, Yamamoto Y, Eberle D, Shimada T, Kamei N, Park HS, Sasorith S, Woo JR, et al. 2016 Adipose natural killer cells regulate adipose tissue macrophages to promote insulin resistance in obesity. Cell Metabolism 23 685-698. (https://doi.org/10.1016/j. cmet.2016.03.002)

Male V, Nisoli I, Gascoyne DM \& Brady HJM 2012 E4BP4: an unexpected player in the immune response. Trends in Immunology 33 98-102. (https://doi.org/10.1016/j.it.2011.10.002)

Manikandan P \& Nagini S 2018 Cytochrome P450 structure, function and clinical significance: a review. Current Drug Targets 19 38-54. (https://doi.org/10.2174/1389450118666170125144557)

Noshiro M, Usui E, Kawamoto T, Kubo H, Fujimoto K, Furukawa M, Honma S, Makishima M, Honma K-I \& Kato Y 2007 Multiple mechanisms regulate circadian expression of the gene, for cholesterol 7 alpha-hydroxylase (Cyp7a), a key enzyme in hepatic bile acid biosynthesis. Journal of Biological Rhythms 22 299-311. (https://doi.org/10.1177/0748730407302461)

Ohno T, Onishi Y \& Ishida N 2007 The negative transcription factor E4BP4 is associated with circadian clock protein PERIOD2. Biochemical and Biophysical Research Communications 354 1010-1015. (https://doi.org/10.1016/j.bbrc.2007.01.084)

Partch CL, Green CB \& Takahashi JS 2014 Molecular architecture of the mammalian circadian clock. Trends in Cell Biology 24 90-99. (https:// doi.org/10.1016/j.tcb.2013.07.002)

Petersen MC, Vatner DF \& Shulman GI 2017 Regulation of hepatic glucose metabolism in health and disease. Nature Reviews: Endocrinology 13 572-587. (https://doi.org/10.1038/nrendo.2017.80)

Preidis GA, Kim KH \& Moore DD 2017 Nutrient-sensing nuclear receptors PPARalpha and FXR control liver energy balance. Journal of Clinical Investigation 127 1193-1201. (https://doi.org/10.1172/ JCI88893) 
Ramakrishnan SK, Taylor M, Qu A, Ahn SH, Suresh MV, Raghavendran K, Gonzalez FJ \& Shah YM 2014 Loss of von HippelLindau protein (VHL) increases systemic cholesterol levels through targeting hypoxia-inducible factor 2 alpha and regulation of bile acid homeostasis. Molecular and Cellular Biology 34 1208-1220. (https:// doi.org/10.1128/MCB.01441-13)

Rana JS, Mukamal KJ, Morgan JP, Muller JE \& Mittleman MA 2003 Circadian variation in the onset of myocardial infarction - effect of duration of diabetes. Diabetes 52 1464-1468. (https://doi. $\operatorname{org} / 10.2337 /$ diabetes.52.6.1464)

Ravnskjaer K, Madiraju A \& Montminy M 2016 Role of the cAMP pathway in glucose and lipid metabolism. Handbook of Experimental Pharmacology 233 29-49. (https://doi.org/10.1007/164_2015_32)

Rui L 2014 Energy metabolism in the liver. Comprehensive Physiology 4 177-197. (https://doi.org/10.1002/cphy.c130024)

Shimano H 2001 Sterol regulatory element-binding proteins (SREBPs): transcriptional regulators of lipid synthetic genes. Progress in Lipid Research 40 439-452. (https://doi.org/10.1016/s01637827(01)00010-8)

Shin DJ \& Osborne TF 2009 FGF15/FGFR4 integrates growth factor signaling with hepatic bile acid metabolism and insulin action. Journal of Biological Chemistry 284 11110-11120. (https://doi. org/10.1074/jbc.M808747200)

Sugden MC, Bulmer K, Gibbons GF, Knight BL \& Holness MJ 2002 Peroxisome-proliferator-activated receptor-alpha (PPARalpha) deficiency leads to dysregulation of hepatic lipid and carbohydrate metabolism by fatty acids and insulin. Biochemical Journal $\mathbf{3 6 4}$ 361-368. (https://doi.org/10.1042/BJ20011699)

Takiguchi T, Tomita M, Matsunaga N, Nakagawa H, Koyanagi S \& Ohdo S 2007 Molecular basis for rhythmic expression of CYP3A4 in serum-shocked HepG2 cells. Pharmacogenetics and Genomics 17 1047-1056. (https://doi.org/10.1097/FPC.0b013e3282f12a61)

Tong X, Muchnik M, Chen Z, Patel M, Wu N, Joshi S, Rui L, Lazar MA \& Yin L 2010 Transcriptional repressor E4-binding protein 4 (E4BP4) regulates metabolic hormone fibroblast growth factor 21 (FGF21) during circadian cycles and feeding. Journal of Biological Chemistry 285 36401-36409. (https://doi.org/10.1074/jbc.M110.172866)

Tong X, Zhang D, Buelow K, Guha A, Arthurs B, Brady HJ \& Yin L 2013 Recruitment of histone methyltransferase G9a mediates transcriptional repression of FGF21 gene by E4BP4 protein. Journal of Biological Chemistry 288 5417-5425. (https://doi.org/10.1074/jbc. M112.433482)

Tong X, Li P, Zhang D, VanDommelen K, Gupta N, Rui L, Omary MB \& Yin L 2016 E4BP4 is an insulin-induced stabilizer of nuclear SREBP-1c and promotes SREBP-1c-mediated lipogenesis. Journal of Lipid Research 57 1219-1230. (https://doi.org/10.1194/jlr.M067181)

Tong Y, Zeng P, Zhang T, Zhao M, Yu P \& Wu B 2019 The transcription factor E4bp4 regulates the expression and activity of Cyp3a11 in mice. Biochemical Pharmacology 163 215-224. (https://doi. org/10.1016/j.bcp.2019.02.026)

Tornio A \& Backman JT 2018 Cytochrome P450 in pharmacogenetics: an update. Advances in Pharmacology 83 3-32. (https://doi. org/10.1016/bs.apha.2018.04.007)
Urizar NL, Dowhan DH \& Moore DD 2000 The farnesoid X-activated receptor mediates bile acid activation of phospholipid transfer protein gene expression. Journal of Biological Chemistry 275 39313-39317. (https://doi.org/10.1074/jbc.M007998200)

Wang Y, Viscarra J, Kim SJ \& Sul HS 2015 Transcriptional regulation of hepatic lipogenesis. Nature Reviews: Molecular Cell Biology 16 678-689. (https://doi.org/10.1038/nrm4074)

Wang Y, Viscarra J, Kim S-J \& Sul HS 2016 Transcriptional regulation of hepatic lipogenesis (vol 16, pg 678, 2015). Nature Reviews: Molecular Cell Biology 17 64. (https://doi.org/10.1038/nrm4074)

Wang Y, Kuang Z, Yu X, Ruhn KA, Kubo M \& Hooper LV 2017 The intestinal microbiota regulates body composition through NFIL3 and the circadian clock. Science 357 913. (https://doi.org/10.1126/ science.aan0677)

Wu X, Xie H, Yu G, Hebert T, Goh BC, Smith SR \& Gimble JM 2009 Expression profile of mRNAs encoding core circadian regulatory proteins in human subcutaneous adipose tissue: correlation with age and body mass index. International Journal of Obesity 33 971-977. (https://doi.org/10.1038/ijo.2009.137)

Yang M, Zhang D, Zhao Z, Sit J, Saint-Sume M, Shabandri O, Zhang K, Yin L \& Tong X 2020 Hepatic E4BP4 induction promotes lipid accumulation by suppressing AMPK signaling in response to chemical or diet-induced ER stress. FASEB Journal 34 13533-13547. (https://doi.org/10.1096/fj.201903292RR)

Yin J, Zhang J \& Lu Q 2017 The role of basic leucine zipper transcription factor E4BP4 in the immune system and immunemediated diseases. Clinical Immunology 180 5-10. (https://doi. org/10.1016/j.clim.2017.03.013)

Yoshitane H, Asano Y, Sagami A, Sakai S, Suzuki Y, Okamura H, Iwasaki W, Ozaki H \& Fukada Y 2019 Functional D-box sequences reset the circadian clock and drive mRNA rhythms. Communications Biology 2 300. (https://doi.org/10.1038/s42003-019-0522-3)

Zhang W, Zhang J, Kornuc M, Kwan K, Frank R \& Nimer SD 1995 Molecular-cloning and characterization of NF-IL3A, a transcriptional activator of the human interleukin-3 promoter. Molecular and Cellular Biology 15 6055-6063. (https://doi. org/10.1128/mcb.15.11.6055)

Zhang T, Yu F, Guo L, Chen M, Yuan X \& Wu B 2018 Small heterodimer partner regulates circadian cytochromes 450 and drug-induced hepatotoxicity. Theranostics 8 5246-5258. (https://doi.org/10.7150/ thno.28676)

Zhao M, Zhang T, Yu F, Guo L \& Wu B 2018 E4bp4 regulates carboxylesterase 2 enzymes through repression of the nuclear receptor Rev-erb alpha in mice. Biochemical Pharmacology 152 293-301. (https://doi.org/10.1016/j.bcp.2018.04.005)

Zheng Z, Kim H, Qiu Y, Chen X, Mendez R, Dandekar A, Zhang X, Zhang C, Liu AC, Yin L, et al. 2016 CREBH couples circadian clock with hepatic lipid metabolism. Diabetes 65 3369-3383. (https://doi. org/10.2337/db16-0298)

Zvonic S, Ptitsyn AA, Conrad SA, Scott LK, Floyd ZE, Kilroy G, Wu XY, Goh BC, Mynatt RL \& Gimble JM 2006 Characterization of peripheral circadian clocks in adipose tissues. Diabetes 55 962-970. (https://doi.org/10.2337/diabetes.55.04.06.db05-0873)

Received in final form 12 October 2020

Accepted 29 October 2020

Accepted Manuscript published online 30 October 2020
(C) 2021 Society for Endocrinology Published by Bioscientifica Ltd. Printed in Great Britain 